\title{
Behavioral effects of lesions to the caudate nucleus or mediodorsal thalamus in neonatal, juvenile, and adult rats
}

\author{
JOHN P. VICEDOMINI, JAMES V. CORWIN, and ARTHUR J. NONNEMAN \\ University of Kentucky, Lexington, Kentucky
}

\begin{abstract}
The prefrontal cortex, caudate nucleus, and mediodorsal thalamus are anatomically and behaviorally related. In the present study, the age-dependent lesion effects of caudate nucleus or mediodorsal thalamus damage were assessed using a spatial delayed alternation task known to be sensitive to prefrontal cortex damage. Bilateral electrolytic lesions were placed in the caudate nucleus or mediodorsal thalamus in rats making up three different age-at-surgery groups: neonatal (8-10 days), juvenile (25-27 days), and adult (150-160 days). All animals were allowed a 110-120-day postoperative recovery interval prior to behavioral testing. The subjects given either caudate nucleus or mediodorsal thalamus lesions as neonates were unimpaired in comparison to the juvenile or adult operates sustaining comparable brain damage. Both caudate nucleus and mediodorsal thalamus lesions produced in both juvenile and adult subjects severely retarded acquisition of the alternation task. The results are consistent with the hypothesis that the subcortical components of the prefrontothalamic system mature earlier than do the cortical components.
\end{abstract}

The prefrontal cortex, caudate nucleus $(\mathrm{CN})$, and mediodorsal thalamic nucleus (MD) are anatomically (Beckstead, 1979; Divac, 1979; Divac, Kosmal, Bjorklund, \& Lindvall, 1978; Krettek \& Price, 1977; Leonard, 1969, 1972) and behaviorally (Divac, 1971, 1972; Kolb, 1977; Rosvold, 1972) interrelated. This has led to the suggestion that there is a "prefrontothalamic system"' (Divac, 1971; Kolb, 1977; Rosvold, 1972), a system that has been identified in several mammalian orders (Markowitz \& Pritzel, 1977).

In adult rats, selective lesions to mediofrontal (MF) or orbitofrontal (OF) cortex result in different behavioral impairments. Damage to the MF subfield impairs performance on several behavioral tasks requiring alternation or reversal of place learning. Lesions to the OF subfield leave place learning relatively unaffected, but they impair performance on tasks which require the animal to alternate or inhibit ongoing operant behavior. In addition, hyperactivity, hypodipsia, and hypophagia are often elicited by OF but rarely by MF cortex lesions. This double dissociation of behavioral functions after damage to the two major subdivisions of rat prefrontal cortex has been extensively documented (Divac, 1971; Johnston,

Portions of this report were presented to the International Society for Development Psychobiology, Cincinnati, Ohio, 1979. This research was supported by a summer fellowship presented to J.P.V. from the Graduate School, University of Kentucky. J. V. Corwin is now at the Department of Neuroscience, J. Hillis Miller Health Center, University of Florida, Gainesville, Florida 32610. The address of the other authors is: Department of Psychology, University of Kentucky, Lexington, Kentucky $\mathbf{4 0 5 0 6 .}$
Hart, \& Howell, 1974; Kolb \& Nonneman, 1975; Kolb, Nonneman, \& Singh, 1974; Nonneman \& Corwin, 1981; Wikmark, Divac, \& Weiss, 1973).

When lesions are placed in the CN (Divac, 1972; Gross, Chorover, \& Cohen, 1965; Hannor \& Bader, 1974; Kolb, 1977; Potegal, 1969; Schmaltz \& Isaacson, 1968, 1972) or MD of adult rats (Gross et al., 1965; Kolb, 1977; Means, Harrell, Mayo, \&Alexander, 1974; Means, Hunt, Whiteside, \& Bates, 1973), the constellation of behavioral dysfunction resembles that following damage to the prefrontal neocortex. Although a double dissociation of "prefrontothalamic function" has not yet been clearly identified within the rat $\mathrm{CN}$, it seems likely that such a separation exists, as the afferent and efferent prefrontothalamic fibers course principally through different sectors of CN (Beckstead, 1979; Krettek \& Price, 1977; Leonard, 1972). Interconnections between MF cortex and MD travel through the anterodorsal sectors of $\mathrm{CN}$; those between OF cortex and MD pass through more ventrolateral sectors of $\mathrm{CN}$. Thus, anterodorsal $\mathrm{CN}$ lesions should produce behavioral impairments resembling those following MF cortex damage, while lesions placed in the ventrolateral $\mathrm{CN}$ should result in impairments resembling those seen after OF cortex damage. In a recent study, Thompson, Guilford, and Hicks (1980) reported that deficits in spatial learning ability follow anterodorsal, but not ventrolateral, $\mathrm{CN}$ damage. Their results thus suggest that a demonstration of double dissociation of function within $\mathrm{CN}$ is possible.

It would be difficult to demonstrate different locus- 
specific lesion effects following MD damage, as the surgical target is small and its projections to the prefrontal cortex arise from partially overlapping fields (Beckstead, 1979; Krettek \& Price, 1977).

Not all of the behavioral effects produced by prefrontal cortex damage in adulthood are observed in rats given prefrontal lesions during infancy (Kolb \& Nonneman, 1976, 1978; Kolb \& Whishaw, 1981; Nonneman \& Corwin, 1981). In general, the younger the rat at the time of surgery, the greater the behavioral sparing observed, but the severity of the deficit produced by surgery at a given age depends on the specific behavioral task as well as the prefrontal subfield removed (Kolb \& Nonneman, 1976; Nonneman \& Corwin, 1981). In fact, juvenile rats receiving MF lesions as late as 25 days of age are unimpaired in spatial alternation learning ability (Nonneman \& Corwin, 1981), and no deficit is seen on this same task in infant rats, even after simultaneous removal of both the MF and OF cortex or complete anterior neodecortication (Vicedomini, Corwin, \& Nonneman, 1982). Thus, following early damage to the cortical components of the prefrontothalamic system, considerable sparing of function occurs on a task that is seriously impaired by such damage in adolescent or adult rats.

In the present study, we examined the possibility that similar sparing of function might occur after early damage to the subcortical components of this system. Rats receiving CN or MD lesions as neonates, juveniles, or adults were tested 4 months later for spatial alternation learning ability.

\section{METHODS}

\section{Subjects}

Neonatal (8-10 days old at surgery), juvenile (25-27 days old at surgery), and adult (150-160 days old at surgery) Long-Evans hooded rats of both sexes from the Psychology Department's animal colony were used. For subjects in the neonatal or juvenile surgical groups, litters were culled to eight rats within 2 days of birth. All rats were weaned at 21 days of age and thereafter group housed (3-4 per cage) according to sex until about 75 days of age. For the remainder of the experiment the subjects were housed individually. The colony room environment was maintained at a constant temperature $\left(22^{\circ} \pm 1^{\circ} \mathrm{C}\right)$ and relative humidity $(45 \% \pm$ 5\%). A 12:12 light-dark cycle was maintained, with light onset at 8 a.m. All surgical procedures and behavioral testing were conducted during the light phase.

Neonatal $(n=10)$, juvenile $(n=11)$, and adult $(n=13)$ rats were given bilateral lesions to $\mathrm{CN}$ or MD. Additionally, 7 neonatal and 7 juvenile rats received sham lesions. A split-litter technique was used so that each surgical group was represented in every litter. The neonates were removed from the nest as a litter and returned to their mother as a litter following surgery. All subjects received equivalent postoperative recovery intervals (110-120 days) prior to behavioral testing.

\section{Surgery}

Anesthesia was produced in neonates by Ketaset (Ketamine hydrochloride $100 \mathrm{mg} / \mathrm{cc}$ ), using a 1:12 dilution of the stock solution $(.5 \mathrm{mg} / \mathrm{kg})$ injected im. Chloral hydrate $(330 \mathrm{mg} / \mathrm{kg})$ was used to anesthetize the juvenile and adult operates.
Bilateral electrolytic (anodal dc) lesions were placed in $\mathrm{CN}$ or MD of neonatal and juvenile rats using stereotaxic coordinates obtained from the atlas by Sherwood and Timiras (1970). The stereotaxic coordinates for adult $\mathrm{CN}$ or MD lesions were taken from Pellegrino and Cushman's (1967) atlas. For both $\mathrm{CN}$ and MD lesions at each age, the following current parameters were used: adult, $1.5 \mathrm{~mA}, 20 \mathrm{sec}$; juvenile, $1.5 \mathrm{~mA}, 15 \mathrm{sec}$; neonate, $1.5 \mathrm{~mA}, 10 \mathrm{sec}$. Lesions produced in $\mathrm{CN}$ were intended to destroy only the anterodorsal sector, thus disrupting fibers interconnecting MD and MF cortex. Sham operations produced in neonatal and juvenile rats included all aspects of $\mathrm{CN}$ or MD lesions except that current was not passed through the lesioning electrode.

\section{Behavioral Testing}

The testing apparatus, a wooden T-maze painted flat gray throughout, has been described in previous studies (Kolb \& Nonneman, 1977; Nonneman \& Corwin, 1981). A modification of the spatial delayed alternation procedure described by Wikmark et al. (1973) was used. This spatial alternation task was chosen because performance on this task has been shown to be a reliable indicant of MF cortex integrity (Kolb \& Nonneman, 1977; Nonneman \& Corwin, 1981; Vicedomini et al., 1982).

Prior to initial training, the rats were gentled by daily handling and allowed to explore the maze. During this 7-10-day adaptation phase, food was not present in the maze, and the animals were allowed free access to food in the home cage. Then the animals were placed on a 23-h food deprivation schedule and pretrained 10 trials per day with food (hydrated Purina Rat Chow) available in both goal arms. During this pretraining phase, consecutive responses to the same arm were followed by forced choice to the previously nonchosen arm. This procedure was intended to discourage the formation of side preferences, and to ensure that the animal experienced reward in both goal arms. Pretraining was terminated when the rats ate readily on all trials for 2 consecutive days, a criterion most animals obtained within a few days.

During behavioral testing, the animals were required to spatially alternate their responses. A noncorrection procedure was used, and the position of the food cup on any trial depended on the animals' previous response. The first trial of each training session was always reinforced. On subsequent trials, a correct choice (alternation) was reinforced by $10 \mathrm{sec}$ access to rat chow, after which the food cup containing the chow was moved to the other goal arm for the next trial. On nonalternation trials, when reinforcement was not obtained, the animal was blocked in the unbaited goal arm for $10 \mathrm{sec}$. After each trial, the animal was removed from the goal arm and placed into the startbox for the next trial. An error was scored if the animal entered the same goal arm on two consecutive trials; additional consecutive responses to the same goal arm were scored as perseverative errors. Ten trials per day were given until a criterion of $80 \%$ correct on 2 consecutive days or a maximum of 200 trials was observed.

\section{Histological Procedures}

At the completion of all behavioral testing, the rats were sacrificed with an overdose of chloroform and transcardially perfused with $.9 \%$ saline followed by $10 \%$ Formalin in saline. The brains were removed and kept in 30\% sucrose-10\% Formalin for 2 weeks, and then cut on a freezing microtome at $35 \mu \mathrm{m}$, mounted on slides, and stained with cresyl violet. Every fifth section throughout the extent of the $\mathrm{CN}$ or anterior thalamus was kept. The lesions were assessed by light microscopy and reconstructed on standardized diagrams adapted from the atlas by Pellegrino and Cushman (1967).

\section{RESULTS}

\section{Behavioral}

Figure 1 (upper panel) shows median and mean trials to criterion in acquisition of spatial delayed al- 

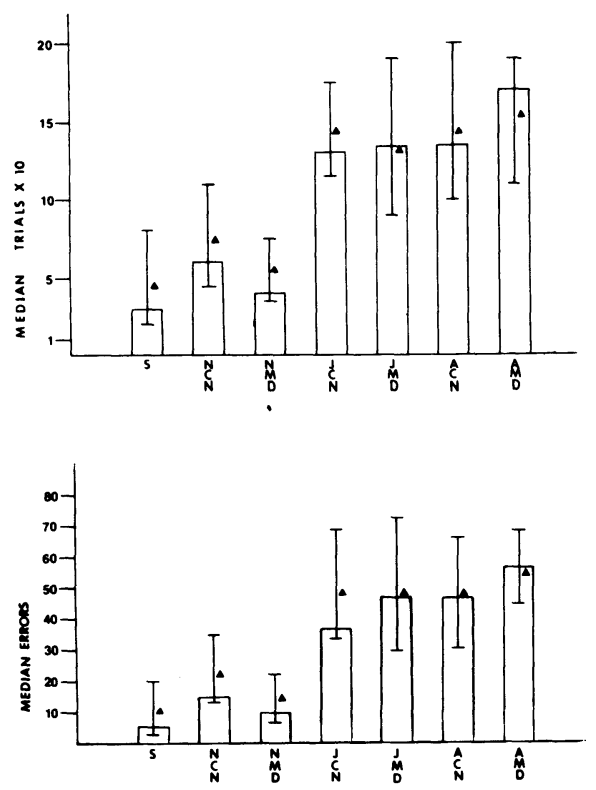

MANN-WHITNEY U

$S$ vs JCN p . . 001 $S$ vs $J M D p=.00$ vs $A C N$ p..00 $S$ vs AMD pr. 001 NCN vs JCN $p=.028$ NCN vs $A C N$ p $=.015$ NMD vs JMDP, 015 NMD vs AMDP $=.016$

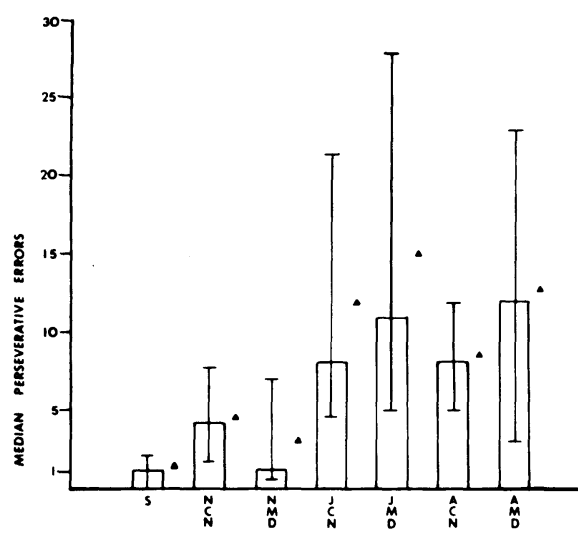

MANN WHITNEY U

S vs JCN p. 001 JMD P. 001 $S$ vs $A C N$ pr. 001 $S$ vs $A M D$ p 1.001 NMD vs JMD $p=026$ NMD VSAMD $p=.048$

Figure 1. Upper panel shows median trials to criterion in acquisition of spatial alternation; center panel shows median errors to criterion; lower panel shows median perseverative errors to criterion. Mean performance is indicated by solid triangles; performance range is indicated by vertical bars. Statistical results presented to the right of each panel are based on a two-tailed analysis. Group abbreviations: $\mathrm{S}=$ sham lesion, $\mathbf{N C N}=$ neonatal caudate nucleus lesion, NMD = neonatal mediodorsal thalamus lesion, $\mathrm{JCN}=$ juvenile caudate nucleus lesion, JMD = juvenile mediodorsal thalamus lesion, $\mathbf{A C N}=$ adult caudate nucleus lesion, and AMD = adult mediodorsal thalamus lesion.

ternation. The center panel shows median and mean errors to criterion, and median and mean perseverative errors to criterion are shown in the lower panel. Statistical comparisons between subjects given similar lesions at different ages and comparisons between lesioned and sham-operated subjects were made using Mann-Whitney U tests. The results of these analyses are shown in the upper right corner of each panel in Figure 1.

The findings of both trials and errors analyses reveal an identical pattern of results. Acquisition performance of neonatal $\mathrm{CN}$ or MD operates did not differ from that of sham operates; however, each one of these groups differed significantly from the groups of subjects given $\mathrm{CN}$ or MD lesions as juveniles or adults. The performance of subjects receiving $\mathrm{CN}$ or MD lesions as juveniles did not differ reliably from those given comparable lesions in adulthood. The results for perseverative errors were the same, except that subjects receiving neonatal $\mathrm{CN}$ lesions differed neither from sham operates nor from subjects receiving $\mathrm{CN}$ lesions as juveniles or adults.

\section{Anatomical}

Reconstructions of maximum and minimum $\mathrm{CN}$ or MD lesions produced in each age group are shown in Figure 2. The smallest $\mathrm{CN}$ lesions in each age group were confined to the head of $\mathrm{CN}$ and extended caudally to include the medialmost anterodorsal sector of $\mathrm{CN}$ bordering the lateral ventricles. The largest $\mathrm{CN}$ lesions in each age group extended from the head of CN caudally into the body of $\mathrm{CN}$. In these subjects, damage was confined to the anterodorsal sector of $\mathrm{CN}$, except in one neonatal operate which sustained modest unilateral damage to ventrolateral $\mathrm{CN}$. The smallest MD lesions in each group produced bilateral damage to the lateral and medial segments of MD (terminology of Krettek \& Price, 1977). Subjects found to have the largest MD lesions suffered variable damage to the anterior nuclei, the anterior reticular nuclei, and the medial aspects of the ventromedial thalamic nuclei. Additionally, one subject in each age group given MD lesions sustained bilateral damage to the habenula and lateral thalamic nucleus.

Both $\mathrm{CN}$ and $\mathrm{MD}$ lesions produced in neonates were larger than those produced in juvenile or adult animals. Thus, the behavioral sparing observed in neonatally operated subjects is not dependent on differences in lesion size between neonatal and juvenile or adult operates. That is, behavioral sparing in neonatal operates occurred despite the fact that these subjects had larger CN or MD lesions.

\section{DISCUSSION}

The results of this study show that considerable sparing of function occurs following neonatal damage to the subcortical components of the prefrontothalamic system of rats, the caudate nucleus (CN) and the mediodorsal thalamus (MD). Comparable results have been obtained following neonatal damage to either prefrontal cortical subfield of rats (Kolb \& Nonneman, 1978; Nonneman \& Corwin, 1981).

In contrast, the effects of damage to the cortical components of the prefrontothalamic system of juvenile rats are less severe than the effects of damage to the subcortical components. In the present study, rats receiving $C N$ or MD lesions at 25 days of age were as impaired as adult operates on a spatial alternation learning task. In a previous study 

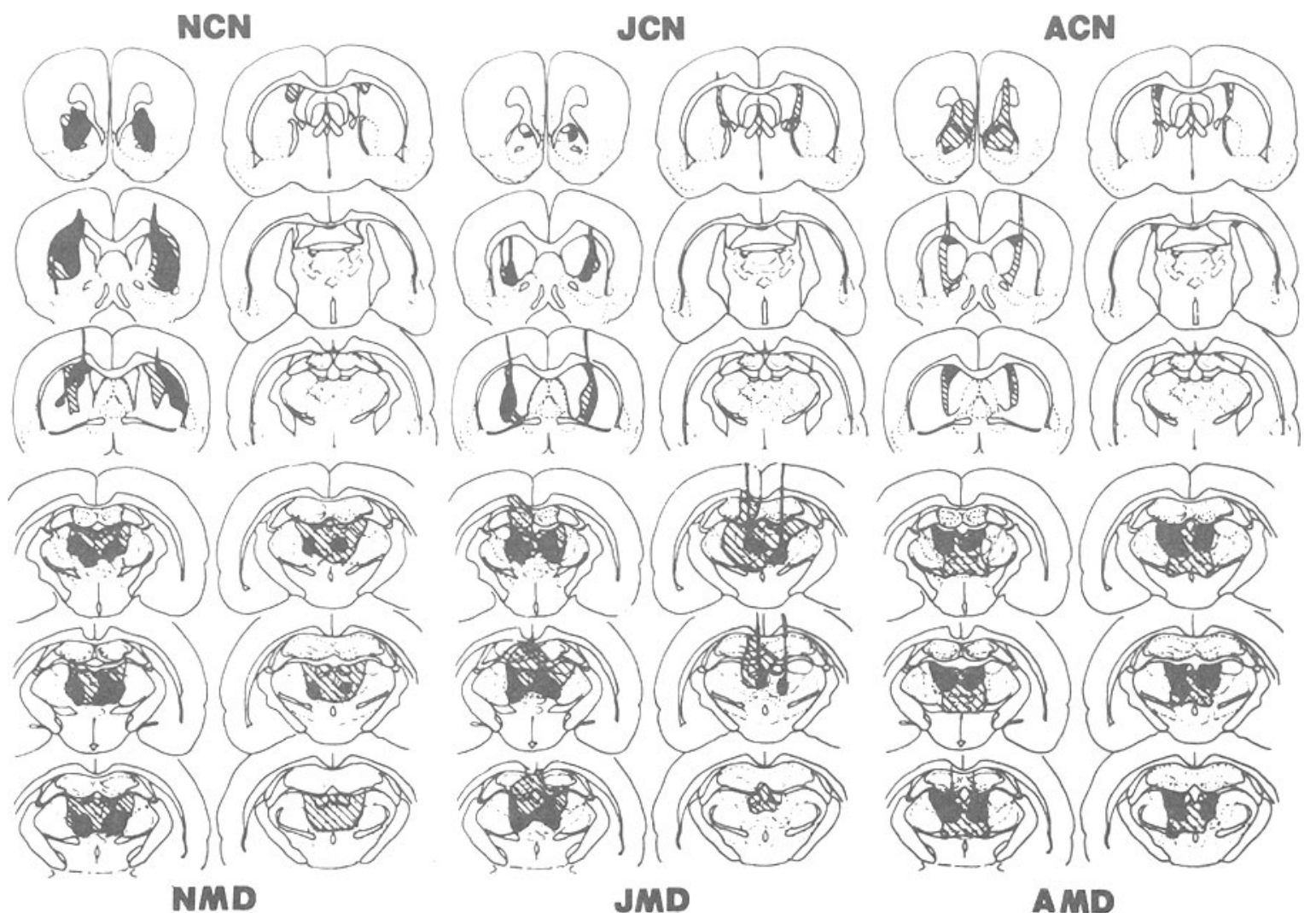

NMD

JMD

AMD

Figure 2. Reconstructions of minimum (shaded area) and maximum (shaded plus striped area) caudate nucleus and mediodorsal thalamus lesions. Group abbreviations are as in Figure 1.

(Nonneman \& Corwin, 1981), rats receiving lesions of the mediofrontal (MF) cortex at 25 days of age were not impaired on the same task, whereas rats receiving comparable lesions at $\mathbf{4 0}$ days of age or later were seriously impaired. These results are consistent with suggestions that the subcortical components of the prefrontothalamic system mature at an earlier age than do the cortical components (Goldman, 1974; Sahley \& Nonneman, 1979).

It does not seem likely that the behavioral sparing observed in this study depends on less complete destruction of the prefrontothalamic system in neonatal operates than in juvenile or adult operates. In fact, the neonatal lesions appeared to be more extensive than those produced in juvenile or adult animals. The $\mathrm{CN}$ lesions presumably destroyed the principle interconnections between MD and MF prefrontal cortex as well as the neurons of the anterodorsal caudate. The MD lesions were quite extensive and destroyed most of the afferent and efferent connections between MF and prefrontal cortex. This evidence of behavioral sparing after complete deafferentation of prefrontal cortex in infant rats is consistent with two recent reports of similar sparing following neonatal anterior decortication that caused almost complete degeneration of MD (Kolb \& Whishaw, 1981; Vicedomini et al., 1982).

\section{REFERENCES}

Beckstead, R. M. An autoradiographic examination of corticocortical and subcortical projections of the mediodorsalprojection (prefrontal) cortex in the rat. Journal of Comparative Neurology, 1979, 184, 43-62.

Divac, I. Frontal lobe system and spatial reversal in the rat. Neuropsychologia, 1971, 9, 175-183.

Divac, I. Neostriatum and functions of prefrontal cortex. Acta Neurobiologiae Experimentalis, 1979, 32, 461-477.

Divac, I. Patterns of subcortico-cortical projections as revealed by somatopetal horseradish peroxidase tracing. Neuroscience, $1979,4,455-461$.

Divac, I., Kosmal, A., Bjorklund, A., \& Lindvall, 0. Subcortical projections to the prefrontal cortex in the rat as revealed by the horseradish peroxidase technique. Neuroscience, 1978, 3, 785-796.

Goldman, P. S. An alternative to developmental plasticity: Heterology of CNS structures in infants and adults. In D. G. Stein, J. J. Rosen, \& N. Butters (Eds.), Plasticity and recovery of function in the central nervous system. New York: Academic Press, 1974.

Gross, C. G., Chorover, S. L., \& Cohen, S. M. Caudate, cortical, hippocampal and dorsal thalamic lesions in rats: Alternation and Hebb-Williams maze performance. Neuropsychologia, 1965, 3, 53-68.

HANnor, R., \& BADER, A. A comparison of frontal pole, anterior median and caudate nucleus lesions in the rat. Physiology \& Behavior, 1974, 13, 513-521.

Johnston, V. S., HART, M., \& Howell, W. The nature of the medial wall deficit in the rat. Neuropsychologia, 1974, 12, 497-503. 
KolB, B. Studies on the caudate-putamen and dorsomedial thalamic nucleus of the rat: Implications for mammalian frontallobe functions. Physiology \& Behavior, 1977, 18, 237-244.

Kolb, B., \& Nonneman, A. J. Prefrontal cortex and the regulation of food intake in the rat. Journal of Comparative and Physiological Psychology, 1975, 88, 806-815.

Kolb, B., \& Nonneman, A. J. Functional development of prefrontal cortex in rats continues into adolescence. Science, 1976, 193, 335-336.

Kolb, B., \& Nonneman, A. J. Sparing of function in rats with early prefrontal cortex lesions. Brain Research, 1978, 151, 135-148.

Kolb, B., Nonneman, A. J., \& Singh, R. K. Double dissociation of spatial impairments and perseveration following selective frontal lesions in rats. Journal of Comparative and Physiological Psychology, 1974, 87, 772-780.

Kolb, B., \& Whishaw, I. Q. Neonatal frontal lesions in the rat: Sparing of learned but not species-typical behavior in the presence of reduced brain weight and cortical thickness. Journal of Comparative and Physiological Psychology, 1981, 95, 863-879.

Krette K, J. E., \& Price, J. L. The cortical projections of the mediodorsal nucleus and adjacent thalamic nuclei in the rat. Journal of Comparative Neurology, 1977, 171, 157-192.

Leonard, C. M. The prefrontal cortex of the rat. I. Cortical projection of the mediodorsal nucleus. II. Efferent connections. Brain Research, 1969, 12, 321-343.

LEONARD, C. M. The connections of the dorsomedial nuclei. Brain, Behavior, and Evolution, 1972, 6, 524-541.

Markowitsch, J. G., \& Pritzel, M. Comparative analysis of prefrontal learning functions in rats, cats, and monkeys. Psychological Bulletin, 1977, 84, 817-837.

Means, L. W., Harrell, T. H., Mayo, E. S., \& Alexander, G. B. Effects of dorsomedial thalamic lesions on spontaneous alternation, maze, activity, and runway performance in the rat. Physiology \& Behavior, 1974, 12, 973-979.

Means, L. W., Hunt, M. W., Whiteside, R. R., \& Bates, T. W. Deficient acquisition and retention of single-alternation go, no-go in rats with medial thalamic lesions. Physiological Psychology, 1973, 1, 287-291.
Nonneman, A. J., \& Corwin, J. V. Differential effects of prefrontal cortex ablation in neonatal, juvenile, and young adult rats. Journal of Comparative and Physiological Psychology, 1981, 95, 588-602.

Pellegrino, L. J., \& Cushman, A. J. A stereotaxic atlas of the rat brain. New York: Appleton-Century-Crofts, 1967.

Potegal, M. Role of the caudate nucleus in spatial orientation of rats. Journal of Comparative and Physiological Psychology, $1969,69,756-764$.

Rosvold, H. E. The frontal lobe system: Cortical-subcortical interrelationships. Acta Neurobiologiae Experimentalis, 1972, 32, 439-460.

Sahley, C. L., \& Nonneman, A. J. Sparing and recovery of function within the prefrontal system of the infant rat. Neuroscience Abstracts, 1979, 5, 635.

Schmaltz, L. W., \& IsaAcson, R. L. Effects of caudate and frontal lesions on retention and relearning of a DRL schedule. Journal of Comparative and Physiological Psychology, 1968, 65, 343-348.

Schmaltz, L. W., \& Isaacson, R. L. Effect of caudate and frontal lesions on acquisition and extinction of an operant response. Physiology \& Behavior, 1972, 9, 155-159.

Sherwood, N. M., \& Timiras, P. S. A stereotaxic atlas of the developing rat brain. Berkeley: University of California Press, 1970.

Thompson, W. G., Guilford, M. O., \& Hicks, L. H. Effects of caudate and cortical lesions on place and response learning in rats. Physiological Psychology, 1980, 8, 473-479.

Vicedomini, J. P., Corwin, J. V., \& Nonneman, A. J. Role of residual anterior neocortex in recovery from neonatal prefrontal lesions in the rat. Physiology \& Behavior, 1982, 28, 797-807.

Wikmark, R. G. E., Divac, I., \& Weiss, R. Retention of spatial delayed alternation in rats with lesions in the frontal lobes. Brain, Behavior, and Evolution, 1973, 8, 329-339.

(Manuscript received February 12, 1982; revision accepted for publication May 27, 1982.) 